\title{
Rancang Bangun Pendeteksi Letak Material di Rak Gudang PLN (Perusahaan Listrik Negara) Menggunakan SIM-800L ARDUINO
}

\author{
Faisal Bachtiar \\ Program Studi Teknik Elektro, \\ Fakultas Teknik Universitas \\ Muhammadiyah Ponorogo, \\ Jawa Timur, Indonesia \\ faisalbachtiar6@gmail.com
}

\author{
Desriyanti \\ Program Studi Teknik Elektro, \\ Fakultas Teknik Universitas \\ Muhammadiyah Ponorogo, \\ Jawa Timur, Indonesia \\ yunandes@gmail.com
}

\author{
Didik Riyanto \\ Program Studi Teknik Elektro, \\ Fakultas Teknik Universitas \\ Muhammadiyah Ponorogo, \\ Jawa Timur, Indonesia \\ ndoroboys@gmail.com
}

\begin{abstract}
Sebagai perusahaan BUMN (Badan Usaha Milik Negara) ketenagalistrikan, PT PLN (Perusahaan Listrik Negara) Persero ULP(Unit Layanan Pelanggan) Pacitan mempunyai proyek pembangunan infrastruktur kelayakan material listrik. Di perusahaan disediakan puluhan rak gudang penyimpanan material listrik. Rak gudang tersebut difungsikan agar material mudah didata, akan tetapi proses pendataan material masuk dan keluar stok barang di dalam rak gudang masih manual. Material komponen listrik yang beragam jenis dengan struktur gudang yang luas dan model rak gudang bertingkat dirasakan kurang efisien tanpa diimbangi teknologi informasi tata letak material. Sumber data pada penelitian ini menggunakan library research dan desain sistem pada penentuan spesifikasi komponen komponen alat. Perancangan pendeteksi letak material di rak gudang menggunakan LED (Ligt Emitting Dioda) sebagai indikator letak material, SIM800L sebagai komunikasi dua arah, LCD 4x16 sebagai tampilan informasi, print thermal sebagai data pengeluaran barang, WiFi ESP8266 sebagai komunikasi dengan database php myAdmin dan arduino mega 2560 sebagai mikrokontroler sehingga dapat cepat, tepat dan akurat dalam proses pencarian barang. Dengan kondisi rangkaian yang dapat bekerja dengan baik, sistem memberikan informasi berupa pesan singkat SMS (Short Message System) letak material yang dibutuhkan, dengan indikator lampu led menyala pada setiap rak penyimpanan, print out dari print thermal dan update database material di PT PLN (Persero) ULP Pacitan.
\end{abstract}

Kata Kunci-Information, Warehouse, PLN ULP Pacitan, Arduino, SMS

\section{Pendahuluan (HeAding 1)}

Infomasi merupakan unsur yang membangun fungsi manajemen, yang terdiri dari perencanaan, pengoperasian dan pengendalian. Sebagai perusahaan BUMN(Badan Usaha Milik Negara) ketenagalistrikan, PT PLN (Perusahaan Listrik Negara) Persero ULP(Unit Layanan Pelanggan) Pacitan mempunyai proyek pembangunan infrastruktur kelayakan material listrik. Di perusahaan disediakan puluhan rak gudang penyimpanan material listrik. Rak gudang tersebut difungsikan agar material mudah didata. Proses pendataan material masuk dan keluar stok barang di dalam rak gudang masih dilakukan secara manual, tanpa adanya informasi letak posisi rak yang digunakan.

Material komponen listrik yang beragam jenis dengan struktur gudang yang luas dan model rak gudang bertingkat dirasakan kurang efisien tanpa diimbangi teknologi informasi tata letak material. Berdasarkan uraian yang ada, maka dilakukan penelitian Pendeteksi Letak Material Di Rak Gudang PLN Menggunakan SIM-800L Arduino Mikrokontroler Atmega 2560”.

\section{BAHAN DAN METODE}

Metode yang dipakai dalam proses pembuatan alat yang akan dirangkai, dibahas komponen-komponen pada perakitan alat, langkah-langkah perencanaan, dan perangkat yang akan digunakan dalam proses pembuatan alat. Prosedur penelitian di gambarkan pada diagram alir berikut:

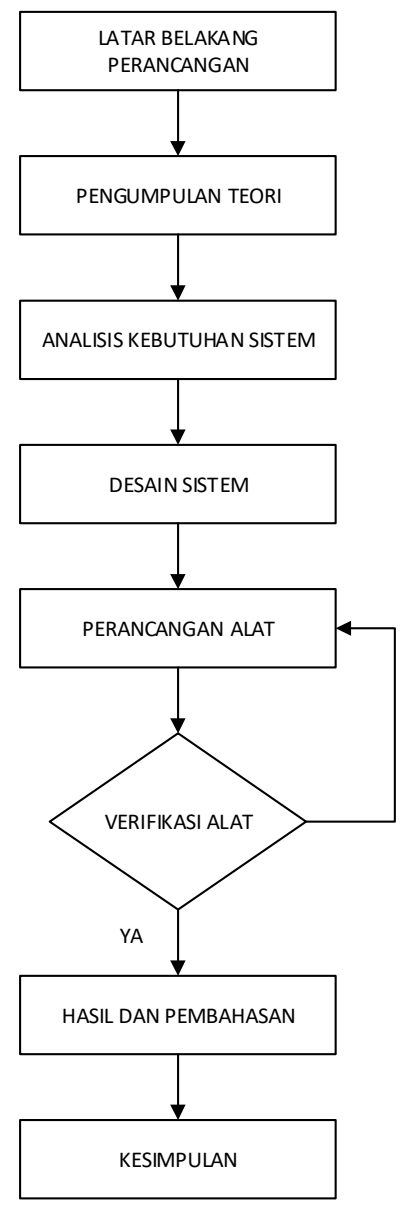

Gambar 1 Diagram alir Penelitian Penjelasan mengenai diagram alir : 


\section{A. Latar belakang Perancangan}

Penelitian ini diawali dengan latar belakang masalah yang mendukung terciptanya suatu rancangan untuk membatu memecahkan masalah dan menjadi tujuan perancangan dasar sistem informasi letak material listrik pada gudang PT.PLN (persero) ULP Pacitan melalui sistem SMS (Short Message System).

\section{B. Memelihara Pengumpulan Teori}

Pada tahap ini dikumpulkan dasar dasar teori perancangan malalui media buku, ebook, jornal, dan internet.

\section{Analisis Kebutuhan Sistem.}

Sistem terbentuk dari kumpulan komponen yang bekerja secara bersama sama untuk mencapai suatu tujuan. Kebutuhan komponen pokok yang harus terpenuhi di dalam perancangan alat adalah sebagai berikut:

TABEL 2.1 ANALISIS KEBUTUHAN KOMPONEN RANCANGAN ALAT

\begin{tabular}{lc}
\hline \multicolumn{1}{c}{ Komponen } & Jumlah \\
\hline Arduino Uno & 1 \\
LCD M1632 & 1 \\
Modul SIM 800L & 1 \\
LED & 10 \\
Regulator DC to DC & 1 \\
\hline
\end{tabular}

\section{Diagram Block Sistem}

Diagram Block informasi letak material di rak gudang dengan menggunakan SMS modem GSM SIM 800L terdiri dari dua block sistem. Desain sistem perangkat keras (hardware) dan perangkat lunak(software). Rancangan keseluruhan ditunjukkan dalam diagram blok berikut:

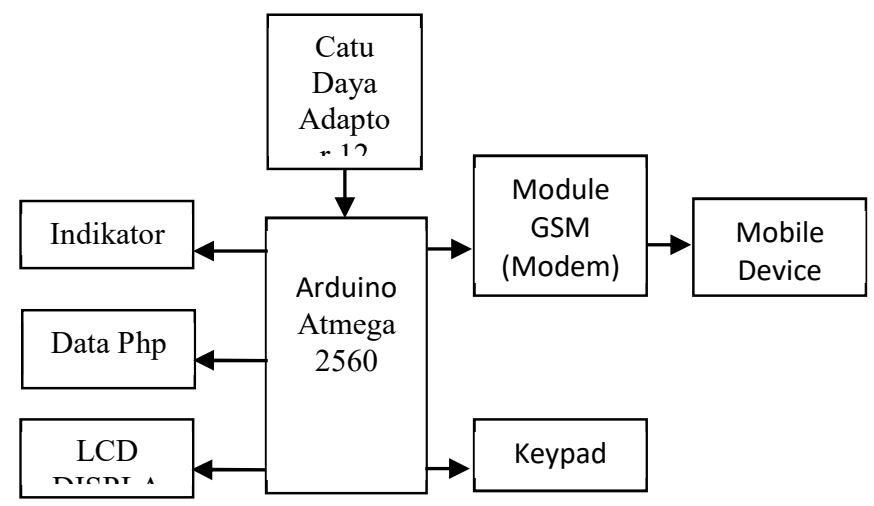

Gambar 2 Diagram block sistem perangkat keras

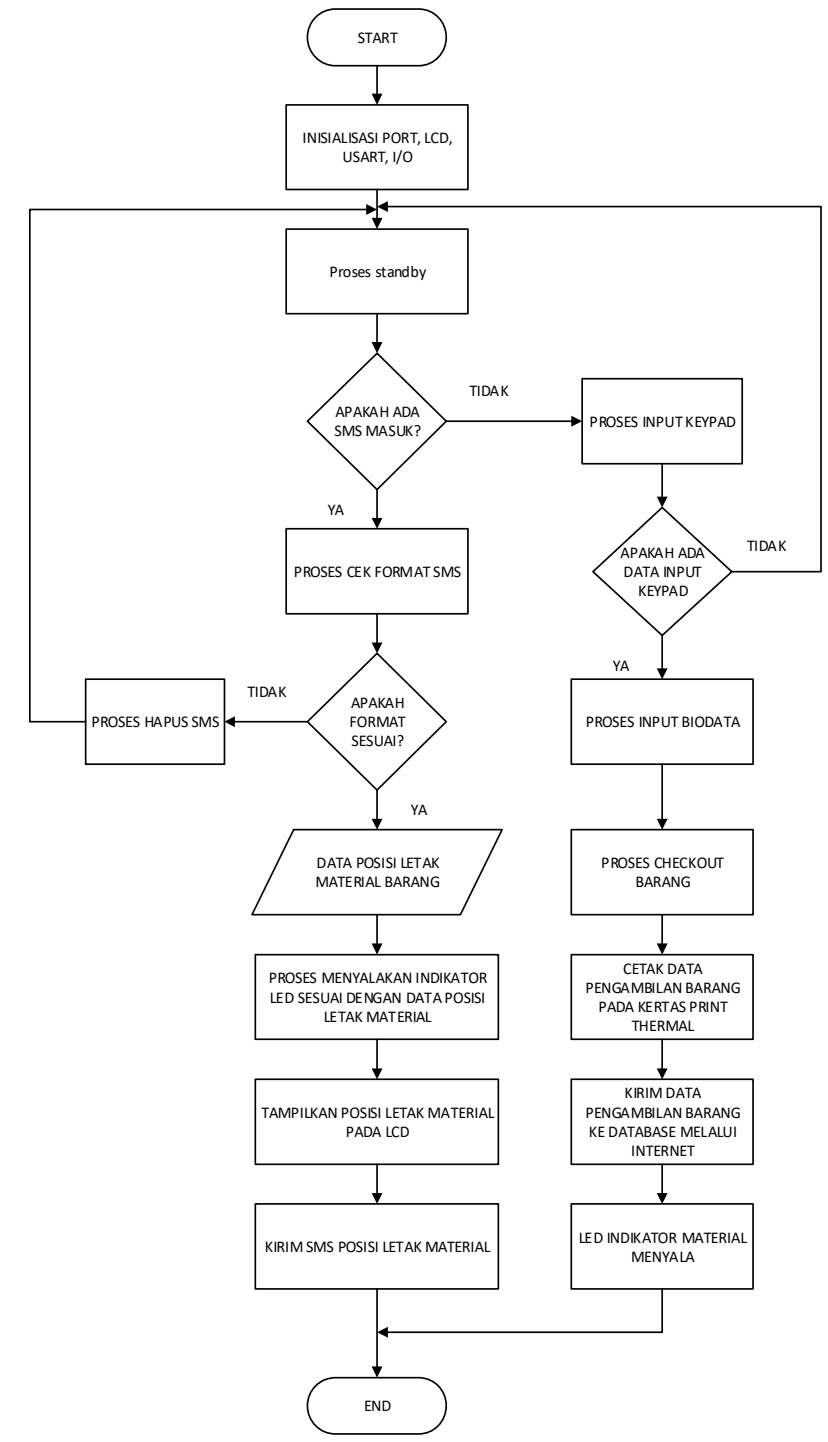

Gambar 3 Flowchart program rancangan keseluruhan

\section{HASIL DAN PEMBAHASAN}

Tahap ini akan dilakukan sebuah pengujian dari rangkaian yang sudah dirancang ke bentuk hardware rancang bangun Sistem Informasi Letak Material di Rak Gudang Dengan Menggunakan SMS Modem GSM SIM-800L Arduino sesuai rangkaian yang sudah dijelaskan sebelumnya. Pengujian dapat dilakukan dengan kesiapan hardware keseluruhan pada gambar berikut.

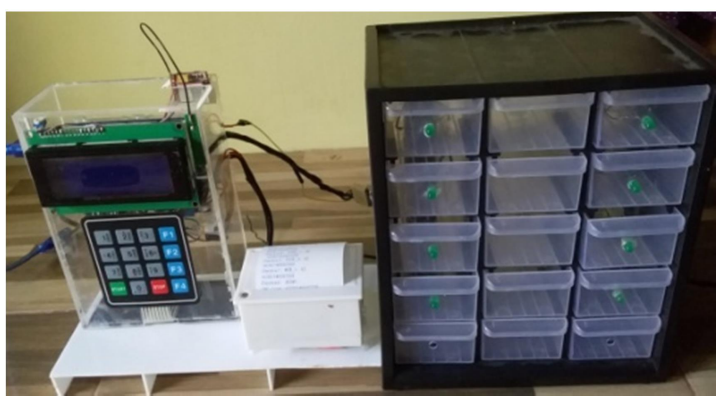

Gambar 4 Hardware Keseluruhan Rancangan Alat

Pengujian akan dilakukan dengan urutan pengujian power supply, pengujian LCD, pengujian modul SIM800L dan pengujian indikator LED material gudang. 
1. Pengujian power supply ini dilakukan dengan memberikan variasi tegangan untuk mengetahui power supply yang cocok digunakan pada Arduino. Alat bantu pengujian menggunakan regulator tegangan DC LM2596 dengan displai seven segment sebagai informasi output tegangan. Berikut hasil pengujian power supply arduino :
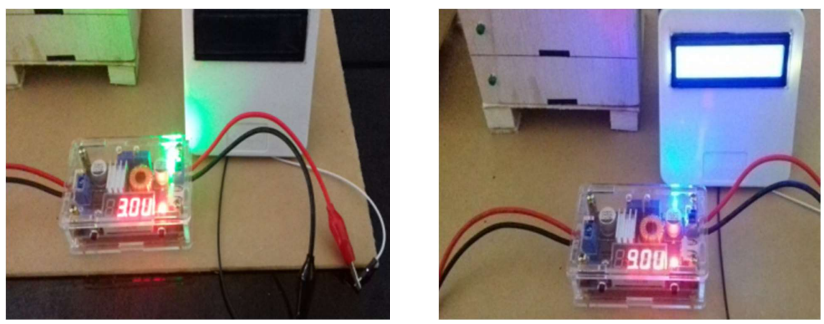

Gambar 5 Pengujian Power Supply Arduino

2. Pengujian modul lcd hanya bisa dilakukan dengan menanamkan sebuah program ke dalam arduino untuk memastikan koneksi berjalan dengan baik, program yang dibuat dengan bantuan software Arduino IDE, berikut uji coba lcd dengan memasukkan listing program sebagai berikut:
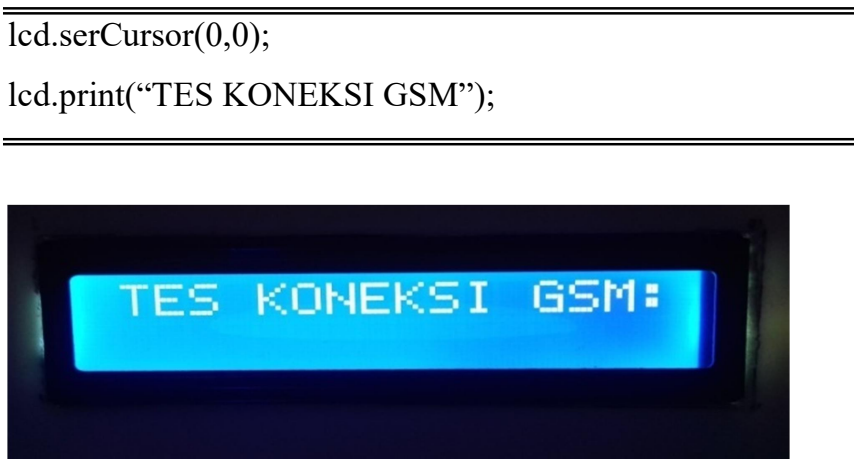

Gambar 6 Hasil Pengujian LCD

3. Pengujian Arduino dengan Modul SIM800L memberikan suplai tegangan yang sesuai dengan kebutuhan tegangan modul SIM800L. Pengujian dilakukan dengan mengukur tegangan output dari regulator LM2596, daerah kerja tegangan dari modul SIM800L pada range 3,6V hingga 4,2V DC

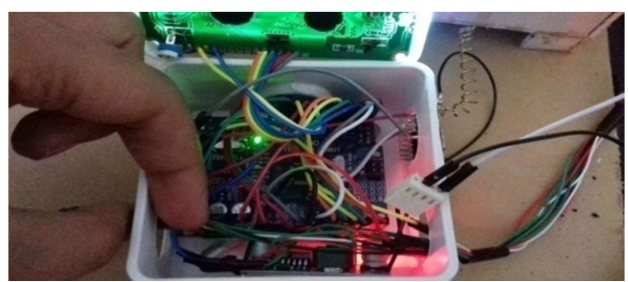

Gambar 7 Proses Pengecekan Tegangan Output LM2596

4. Pengujian modul WiFi ESP8266 dengan mengirimkan perintah AT + Command dan melihat respons dari modul ESP8266. Fitur serial yang digunakan pada board Arduino Mega 2560 menggunakan Serial 1 pada pin $18 \mathrm{Rx}$ (Receiver) dan $19 \mathrm{Tx}$ (Transmitter), berikut potongan urutan program pengujian $\mathrm{AT}+\mathrm{Command}$ modul ESP8266:

\#include "WiFiEspClient.h"

\#include "WiFiEsp.h"

(name)

char ssid[] = "TPLINK";/your network SSID

char pass[] = "Faisal";// your network password

void $\operatorname{setup}()$

\{

// initialize serial for debugging

Serial.begin(115200);

lcd.begin $(20,4)$;

// initialize serial for ESP module

Serial1.begin(115200);

WiFi.init(\&Serial1);

if (WiFi.status ()$==$ WL_NO_SHIELD) \{

Serial.println("WiFi shield not present");

while (true);

\}

lcd.setCursor(0,1);

lcd.print("Koneksi>>WiFi: ");

while ( status $!=$ WL_CONNECTED) \{

Serial.print("Attempting to connect to WPA SSID: ");

Serial.println(ssid);

status $=$ WiFi.begin(ssid, pass);

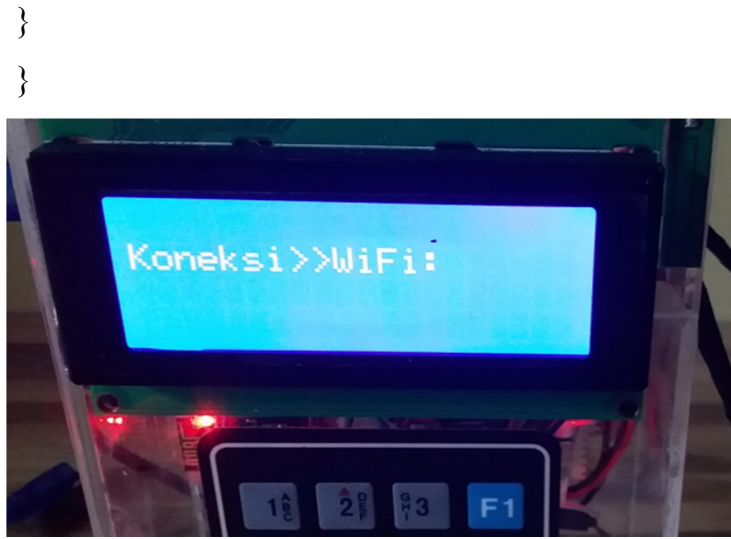

Gambar 7 Proses Koneksi dengan Internet

5. Pengujian print thermal dilakukan dengan mengambil library yang diperlukan untuk mempermudah akses memerintah print thermal untuk mencetak karakter pada kertas thermal. Library yang dibutuhkan yaitu Adafruit Thermal.h, selanjutnya dilakukan proses definisi pin yang digunakan yaitu pin 5 dan 6 sebagai mode softwareSerial.h koneksi antara arduino mega 2560 dengan print thermal, berikut program testing pengujian print thermal:

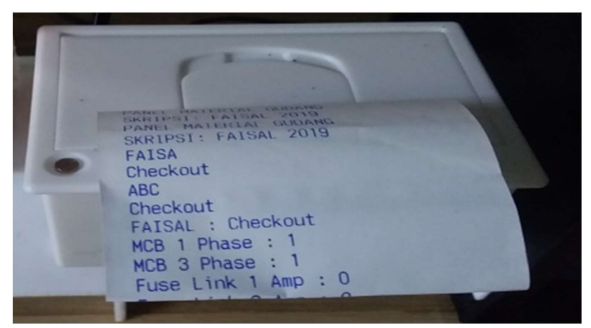


Gambar 8 Hasil Pengujian Akses Print Thermal dengan Arduino

f. Pengujian keypad $4 \times 4$ dilakukan pada proses memasukkan biodata user yang akan melakukan pengambilan material barang, keypad yang digunakan memliki dua fungsi bisa input data nilai angka, maupun karakter, data yang diinputkan ditampilkan pada layar lcd. Berikut listing program proses memasukkan biodata user melalui keypad:

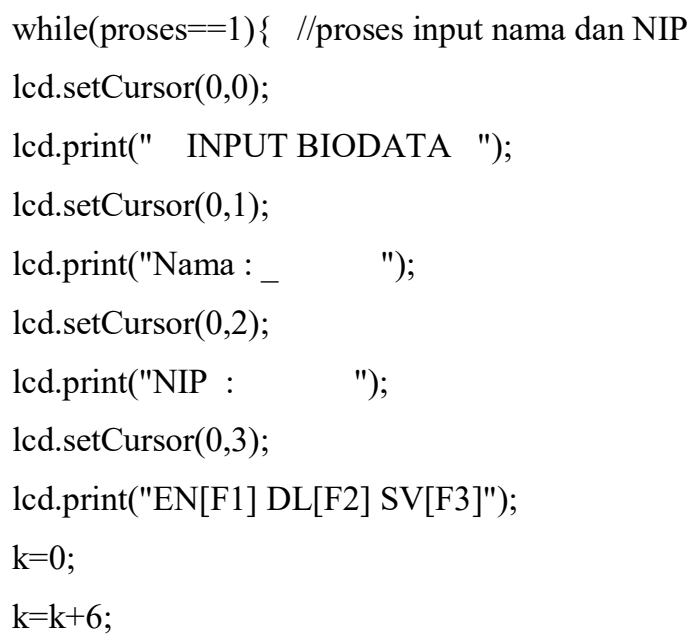
0

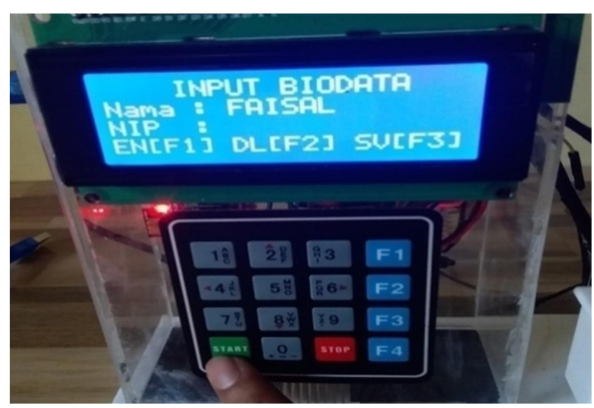

Gambar 9 Hasil Input Biodata User Melalui Keypad

6. Pengujian Arduino dengan indikator LED dilakukan dengan memberikan logika high dan low pada pin pengendali rangkaian LED, pin yang digunakan pada rangkaian yaitu pin 22 hingga 32 .

7. Pengujian database web server dilakukan dengan menghubungkan program php di dalam Notepad++ dengan database di phpMyAdmin. Program keseluruhan dari proses parsing data di lampirkan pada lampiran 2, 3, dan 4. Berikut hasil pengujian web server database.

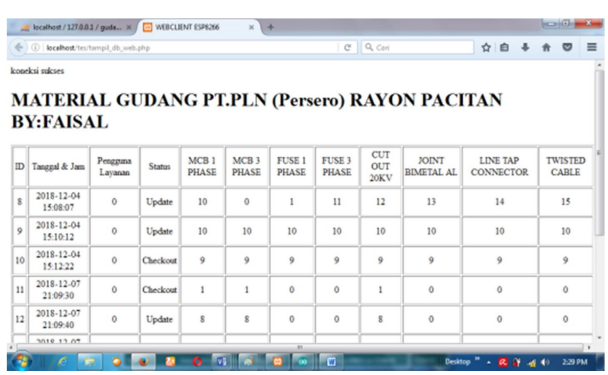

Gambar 10 Hasil Pengujian Database Web Server

8. Pengujian sistem kerja keseluruhan rancangan alat di lakukan dengan memasukkan program keseluruhan di dalam IC Mikrokontroler ATmega2560 pada bord Arduino Uno, prinsip kerja dari keseluruhan rancangan dikendalikan dari SMS operator yang menginginkan suatu material barang di gudang.

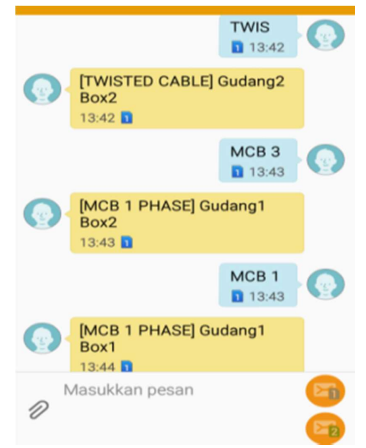

Gambar 11 Pesan SMS Balasan dari Rancangan Alat

\section{KESIMPULAN}

Berdasarkan hasil pengujian dapat disimpulkan bahwa:

a. Rangkaian bekerja dengan baik, ketika ada sms masuk rancangan mampu membaca dan mencetak material yang keluar. 
b. Rangkaian indikator pada setiap rak gudang bekerja dengan baik tanpa ada kendala, ketika format sms yang masuk sesuai dengan kode material barang LED indikator dari salah satu rak yang sudah dikodekan menyala..

\section{DAFTAR PUSTAKA}

[1] Alif, R. (2016). Implementasi Sistem Peminjaman dan Pengembalian Buku dengan Teknologi RFID di Perpustakaan Jurusan Teknik Elektro. Universitas Negeri Semarang.

[2] Andrianto, D. (2017). Arduino Belajar Cepat dan Pemrograman. Bandung: Informatika.

[3] Jogiyanto, HM, MBA, Akt, Ph.D. (1999). Pengenalan Komputer Dasar Ilmu Komputer, Pemograman, Sistem Informasi dan Intelegensi. Yogyakarta : Andi offset.

[4] Jogiyanto HM. (2001). analisis dan desain sistem informasi pendekatan terstruktur. Yogyakarta : Andi offset.
[5] Nurcahyo, S. (2012). Aplikasi dan teknik pemrograman mikrokontroler AVR Atmel. Yogyakarta: Andi offset.

[6] Ridha, A. (2015). Rancang Bangun Loker Penitipan Barang Menggunakan Barcode KTM dan PIC Berbasis Arduino. Universitas Muhammadiyah Malang.

[7] Seiko Instrument Inc. (1987). LCD M1632 User Manual. Aplplication Note: AN.No.1632.711E, 31.

[8] SIMCOM. (2013). Datasheet. SIM800L_Hardware_Design_V1.00, Copyright $(\odot$ Shanghai Simcom Wireless Solutions Ltd 2013.

[9] SIMCOM. (2015). Datasheet. SIM800 Series AT Command Manual_V1.09 2015/08/03.pdf. Copyright (C) Shanghai Simcom Wireless Solutions Ltd 2015 .

[10] D Riyanto. (2017). Perancangan Sistem Informasi Geografis Untuk Pemetaan Sebaran Pasien Keterbelakangan Mental Di Kabupaten Ponorogo. Universitas Muhammadiyah Ponorogo. 